Korean J Ophthalmol 2016:30(4):316-317 http://dx.doi.org/10.3341/kjo.2016.30.4.316

\section{Macular Choroidal Thickness and Volume Measured by Swept-source Optical Coherence Tomography in Healthy Korean Children}

Dear Editor,

We read the article entitled "Macular choroidal thickness and volume measured by swept-source optical coherence tomography in healthy Korean children" by Lee et al. [1] with great interest. The authors measured the thickness and volume of the choroid in healthy Korean children using optical coherence tomography. They examined 80 eyes of 40 healthy children and teenagers $(<18$ years), and compared them with 44 eyes of 35 healthy adults ( $\geq 18$ years). The authors discovered that overall macular choroidal thickness (CT) and volume were significantly greater in children and teenagers compared to adults. The pediatric subfoveal choroid was prone to thinning with increasing age, axial length, and refractive error. We congratulate the authors for their study on macular CT and volume in children and we would like to request more details and their contribution to the article.

$\mathrm{CT}$ is affected by many local and systemic pathologic/ physiologic conditions including diurnal variation, axial length, refractive factor, intraocular pressure, systemic or local diseases and their treatments, and drug use as mentioned in the study [2-4]. However, we would like to ask to the authors if other factors such as smoking, alcohol consumption, exercising, sleeping conditions, caffeinated/ non-caffeinated drink consumption, systemic blood pressure, and body mass index of patients and standardized environmental lighting have been taken into consideration.

Also, gender status within the two groups of children and adults was not disclosed. Although effect of gender on CT was mentioned in the study, we are especially curious if the parameters which apparently affect CT such as menstrual cycle and pregnancy were considered [2]. In conclusion, designing studies to better examine CT can increase the reliability of data obtained and statistical assessments.

Salih Uzun

Department of Ophthalmology, Etimesgut Military Hospital,
Ankara, Turkey

E-mail:s.uzun84@gmail.com

Emre Pehlivan

Department of Ophthalmology, Eskisehir Military Hospital, Eskisehir, Turkey

\section{Conflict of Interest}

No potential conflict of interest relevant to this article was reported.

\section{References}

1. Lee JW, Song IS, Lee JH, et al. Macular choroidal thickness and volume measured by swept-source optical coherence tomography in healthy Korean children. Korean $J$ Ophthalmol 2016;30:32-9.

2. Tan KA, Gupta P, Agarwal A, et al. State of science: choroidal thickness and systemic health. Surv Ophthalmol 2016 Mar 12. http://dx.doi.org/10.1016/j.survophthal.2016.02.007.

3. Nickla DL, Wallman J. The multifunctional choroid. Prog Retin Eye Res 2010;29:144-68.

4. Akay F, Gundogan FC, Yolcu U, et al. Choroidal thickness in systemic arterial hypertension. Eur J Ophthalmol 2016; 26:152-7.

\section{Author reply}

Dear Editor,

We appreciate the interest in our paper [1] and agree that controlling for lifestyle habits or hormonal and gender status that could affect choroidal thickness would increase the reliability of the data.

All examinations took place between 14:00 and 17:00 to reduce the effects of diurnal variations found in some studies [2,3]. Individuals with systemic diseases including hypertension, history of prematurity, previous intraocular surgery, state of pregnancy, or eye history that might affect choroidal thickness were excluded in our study. However, smoking, alcohol use, exercising, sleeping conditions, caffeine, systemic blood pressure, body mass index, gender, and menstrual cycle were not investigated in our study. 
Future studies that control for those factors may help draw a firm conclusion about the healthy individual's choroidal thickness.

Jung Wook Lee, In Seok Song, Ju-hyang Lee, Yong Un Shin, Han Woong Lim

Department of Ophthalmology, Hanyang University College of Medicine, Seoul, Korea

Won June Lee

102 Replacement Depot, Republic of Korea Army, Chuncheon, Korea

Byung Ro Lee

Department of Ophthalmology, Hanyang University College of Medicine, Seoul, Korea

E-mail:brlee@hanyang.ac.kr

\section{Conflict of Interest}

No potential conflict of interest relevant to this article was reported.

\section{References}

1. Lee JW, Song IS, Lee JH, et al. Macular choroidal thickness and volume measured by swept-source optical coherence tomography in healthy Korean children. Korean $J$ Ophthalmol 2016;30:32-9.

2. Brown JS, Flitcroft DI, Ying GS, et al. In vivo human choroidal thickness measurements: evidence for diurnal fluctuations. Invest Ophthalmol Vis Sci 2009;50:5-12.

3. Tan CS, Ouyang Y, Ruiz H, Sadda SR. Diurnal variation of choroidal thickness in normal, healthy subjects measured by spectral domain optical coherence tomography. Invest Ophthalmol Vis Sci 2012;53:261-6. 